\title{
Growth and reproductive biology of the sea star Astropecten aranciacus (Echinodermata, Asteroidea) on the continental shelf of the Catalan Sea (northwestern Mediterranean)
}

\author{
Marc Baeta ${ }^{1,2^{*}}$, Eve Galimany ${ }^{1,3}$ and Montserrat Ramón ${ }^{1,3}$
}

\begin{abstract}
The growth and reproductive biology of the sea star Astropecten aranciacus was investigated on the continental shelf of the northwestern Mediterranean Sea. Sea stars were captured monthly in two bathymetric ranges (5-30 and 50-150 m) between November 2009 and October 2012. Bathymetric segregation by size in A. aranciacus was detected: small individuals inhabit shallow areas $(5-30 \mathrm{~m})$, while large individuals inhabit deeper areas of the continental shelf (50-150 m). Recruitment was recorded twice nearshore but no recruitment was detected offshore during the whole study period. Three cohorts were identified in each bathymetric range and growth rates were estimated. A. aranciacus population exhibited a seasonal growth pattern, being higher from June to October in the nearshore cohorts and from February to October in the offshore ones. Histology and organ indices revealed that spawning likely started in March, coinciding with the spring phytoplankton bloom and the increase in sea water temperature, and extended until June-July. Ratio between males and females was approximately 1:1 throughout the year and in both bathymetrical ranges. The size at first maturity (R50 \%) was estimated to be $R=112 \mathrm{~mm}$. A. aranciacus did not show an inverse relationship between gonad index and pyloric caeca index.
\end{abstract}

Keywords: Asteroidea, Starfish, Mediterranean and echinoderm

\section{Background}

Sea stars play an essential ecological role as high-level predators in the structure and function of intertidal and subtidal benthic communities, where they promote heterogeneity and diversity [23]. Changes in the abundance of these predators can have far-reaching consequences on the population characteristics of many of the invertebrates on which they prey [11]. Despite the ecological importance of sea stars, research has been mainly limited to certain species and to areas where they have an economic impact because they feed on important shellfish or on reef-building corals [28].

*Correspondence: marcbaeta@hotmail.com

${ }^{1}$ Institut de Ciències del Mar (CSIC), Passeig Marítim de la Barceloneta,

37-49, 08003 Barcelona, Spain

Full list of author information is available at the end of the article
Astropecten (Fam. Astropectinidae) is one of the most species-rich genera among sea stars and its members are distributed worldwide, from polar to tropical seas and from intertidal areas to the deep sea [49]. They are voracious predators, feeding mainly on gastropods and bivalves. They have an intra-oral feeding mechanism, swallowing prey intact [11]. In general they exhibit a patchy spatial distribution as a consequence of a combination of biotic (e.g., prey and congener abundance) and abiotic factors (e.g., depth and sediment properties) [36]. Astropecten spp. have a pair of gonads and a pair of pyloric caeca (digestive organs) located in each arm [44]. Gonad and pyloric cecum indices are widely used as indicators of reproductive effort and nutritional condition. Resources stored in pyloric cecum seem to play an important role in the seasonal production of gonads in some asteroid species [29]. 
There is a vast literature on the genus Astropecten worldwide, mainly focusing on their feeding behavior, diet characteristics $[3,11]$ and early stages of development $[22,27]$. However, aspects of their biology such as growth and reproductive biology have been less analyzed than those of other sea star genera [44]. Growth in field populations has been studied in both tropical [43] and temperate waters $[15,35]$. Ventura [44] observed a growth decrease coinciding with the seasonal upwelling season in Brasil. Freeman et al. [15] observed that $A$. irregularis growth in North Wales was highly seasonal, with maximum growth occurring between mid-summer and mid to late autumn. Ventura [44] Astropecten spp. reproduction has been analyzed in temperate $[11,15$, $18]$ and in tropical waters [31, 47, 48]. Reproduction is usually seasonal in temperate waters and spawning takes place with the increase in water temperatures [15]; however, in tropical waters sympatric Astropecten species seem to react differently to changes in sea water temperature and then, spawning occurs at different seasons [44].

Astropecten aranciacus (Linnaeus 1758) inhabits the Mediterranean Sea and the eastern Atlantic from Portugal to Angola, including the Canary, Madeira and Cape Verde Islands. It is one of the largest sea stars in the Mediterranean Sea, with a body diameter of up to $60 \mathrm{~cm}$. It lives on sandy, muddy and detrital bottoms, as well as on seagrass beds, including Zostera, Cymodocea and Posidonia, between 1 and $200 \mathrm{~m}$ depth [42]. A. aranciacus is the dominant species on the continental shelf of the Maresme coast (northwestern Mediterranean Sea), where it co-occurs with other species of the same genus (A. platyacanthus, A. irregularis pentacanthus, A. bispinosus, $A$. spinulosus and $A$. jonstoni) between 5 and $30 \mathrm{~m}$ depth [2]. Baeta and Ramón [3] observed that Astropecten sea stars have niche segregation, showing a partitioning of the resources and occupying different microhabitats to avoid food competition. At depths between 50 and $200 \mathrm{~m}$ in the same area, $A$. aranciacus co-occurs with A. irregularis pentacanthus and other non-congeneric species (Luidia ciliaris, Tethyaster subermis, Peltaster placenta, Anseropoda placenta and Hacelia attenuata) [2].

Astropecten aranciacus has a defined behavioral pattern: it remains buried in the sand during the daytime, emerges just before sunset and looks for prey all night, and buries itself again just a few hours after dawn [37]. In the study area $A$. aranciacus feeds mainly on the bivalves Glycymeris glycymeris and Callista chione, together with the gastropod Cyclope neritea between 5 and $30 \mathrm{~m}$ depth [3]; and almost exclusively on the bivalve Timoclea ovata between 50 and $200 \mathrm{~m}$ depth [2]. Recently, a major decrease in its population has been detected in the Mediterranean Sea [50].
This paper examines for the first time growth and reproduction aspects of $A$. aranciacus. For this purpose, we have analyzed modal progression of size classes, histological sections of gonads and variations of the pyloric caeca and gonadal indices. In addition, the influence of exogenous factors such as photoperiod, sea water temperature and chlorophyll $(\mathrm{Chl} a)$ concentration on the reproductive biology of the species was also analyzed.

\section{Methods \\ Study site}

The study was carried out on the continental shelf of the Catalan Sea (northwestern Mediterranean), between the Tordera River delta (northeast) and the mouth of the Tiana seasonal stream (southwest) (Fig. 1). This area is called the Maresme coast, and it is a reflective, sandy and straight, wave-dominated plain which displays a NE-SW trend. The continental shelf has a mean width of $21 \mathrm{~km}$ and a gradient of between $0.01^{\circ}$ and $10^{\circ}$, with the shelf break occurring at $130 \pm 20 \mathrm{~m}$ [14]. Its seabed consists of coarse to medium sandy bottoms nearshore and mud and/or sandy bottoms offshore [13].

\section{Sampling}

Monthly samples were obtained on the Maresme coast between November 2009 and October 2012. Sampling was performed by fishermen on board two vessels from the Arenys de Mar harbor fishing fleet, which use commercial fishing gears according to their fishing modality (shellfish and trawlers) and fishing grounds. The impossibility of sampling the whole study area with the same gear due to local fishing regulations forced us to subdivide the study site into two nearby areas (Fig. 1): nearshore, where the shellfish fleet operate between 5 and $30 \mathrm{~m}$ depth; and offshore, where trawlers are allowed to operate below $50 \mathrm{~m}$ depth. The strip between 30 and $50 \mathrm{~m}$ depth is not covered by these fishing boats in their daily activities. The nearshore area was sampled during daylight onboard the artisanal fishing boat Esparta (10 m in length; $100 \mathrm{hp}$ ), which belonged to the smooth clam fishery fleet and used clam dredges. The clam dredge consisted of a metal frame (mouth length, $70 \mathrm{~cm}$; mouth height, $53 \mathrm{~cm}$ ), a toothed lower bar and a rectangular metal grid box (mesh size, $29 \times 29 \mathrm{~mm}$ ). Each tow lasted approximately $30 \mathrm{~min}$ at a speed of $1-1.2 \mathrm{~km}$, and the mean towed area was around $800 \mathrm{~m}^{2}$. The offshore area (between 50 and $150 \mathrm{~m}$ depth) was sampled during daylight onboard the small trawl fishing boat San Benito (10.75 m in length; $105 \mathrm{CV}$ ), which targeted black bellied angler (Lophius budegassa) and royal sea cucumber (Parastichopus regalis). The trawl net was cone-shaped, with a mouth $4 \mathrm{~m}$ wide $\times 0.5 \mathrm{~m}$ high and a quadrangular mesh size of $40 \times 40 \mathrm{~mm}$. Each tow lasted approximately 


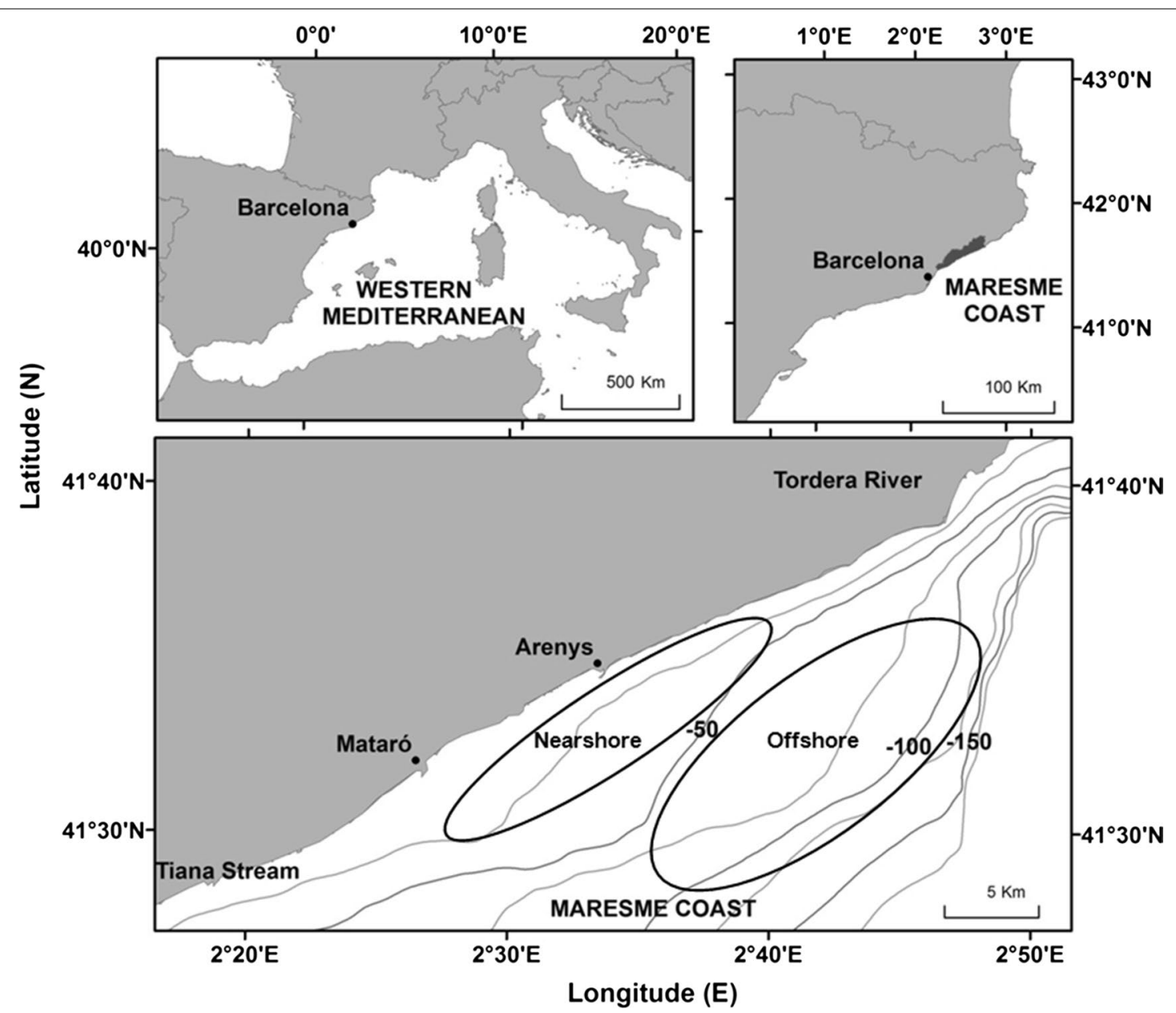

Fig. 1 Study area showing the location of the sampling areas on the Maresme coast (circles) and the 50, 100 and $150 \mathrm{~m}$ isobaths

$2 \mathrm{~h}$ at a speed of $1.8-2 \mathrm{~km}$. All the $A$. aranciacus caught, regardless of the gear used, were transported in a cool box $\left(4{ }^{\circ} \mathrm{C}\right)$ to the laboratory, where they were weighed and measured. The length of the sea stars was defined as $R$, major radius length or distance from the center of the oral disk to the tip of the longest arm, and was measured using calipers to the nearest $0.1 \mathrm{~mm}$.

\section{Growth}

Length-weight relationship was estimated by combining biometrical data from individuals collected monthly between November 2009 and October 2012 in both bathymetrical ranges. The relationship between the length and weight of one organism is usually expressed by the equation $W=a L^{b}$, where $W$ is body weight (g), $L$ is length $(\mathrm{cm}), a$ is the intercept and $b$ is the allometric coefficient. Values of $b$ significantly different from 3 indicated that growth in weight is relatively faster than growth in length (positive allometry $b>3$ ) or lower (negative allometry $b<3$ ).
Nearshore and offshore samples were analyzed separately to study growth due to the different gear selectivity. Sea star length $(R)$ was categorized into $20-\mathrm{mm}$ classes and grouped every 2 months to obtain bimonthly lengthfrequency distributions. Growth was estimated from the modal class progression analysis in the length-frequency distributions, using the Bhattacharya method [5], previously used to examine growth in other asteroids $[7,30]$ and included in the FISAT II software [16]. The parameters of the von Bertalanffy growth function $\left(L_{t}=L_{\infty}(1-\right.$ $\left.e^{-k(t-t 0)}\right)$ were estimated by nonlinear regression using the FiSAT II software package, where, from left to right, $L_{t}$ is the predicted length at time $t(\mathrm{~mm}), L_{\infty}$ is the asymptotic length $(\mathrm{mm}), k$ is the growth constant (year $\left.{ }^{-1}\right), t$ is the age (year) of the $A$. aranciacus, and $t_{0}$ is the age at which $L_{t}=0$ [21].

\section{Reproduction}

All nearshore and offshore individuals collected monthly, from May 2011 to September 2012, were used for 
reproduction analyses. Each sea star was damp-dried and weighed to the nearest $0.001 \mathrm{~g}$. The oral surface was opened by separating the plates along the ambulacral grooves to expose the viscera. The number of immature individuals was annotated, and all gonads from adults were examined (between 18 and 34 gonads per month). Gonads and pyloric caeca of the five arms were removed, damp-dried and weighed to $0.001 \mathrm{~g}$ accuracy. Gonads were fixed in $10 \%$ formalin for $24 \mathrm{~h}$, cleaned with deionized water and preserved with $70 \%$ ethanol. The gonad tissue was dehydrated in graded ethanol, and then infiltrated and embedded with glycol-methacrylate resin. Gonads were cut into 4- $\mu \mathrm{m}$ sections and stained in Lee's methylene blue-basic fuchsin. Microscopic examination of the sections allowed sex determination and assignation of each individual to a gonad maturation state. Development was divided into five stages based on an adaptation of scales used for other asteroid species, where each stage is determined according to the frequency and characteristics of gametes, presence of phagocytes and cell remains, as well as thickness and shape of the gonadal wall $[4,9,10,32,38]$.

The gonadal index (GI) and the pyloric caeca index (PCI) were calculated as [17]:

$$
\frac{\text { Wet organ weight }}{\text { Total body wet weight }} \times 100
$$

Size at first maturation (size at which gonads of $50 \%$ of the individuals are mature, $R 50 \%$ ) was calculated by plotting the percentage of individuals with mature gonads versus size [12]. To analyze the influence of some exogenous factors on the reproductive biology of this species, surface water temperature was obtained from the Barcelona buoy of "Puertos del Estado" $\left(41.32^{\circ} \mathrm{N} / 02.20^{\circ} \mathrm{E}\right)$, photoperiod data from the "Instituto Geográfico Nacional, Ministerio de Fomento" and the monthly Chl $a$ concentration was obtained from MODIS satellite imagery, using a resolution of $4 \mathrm{~km}$ with $0.1 \times 0.1$ degrees areas.

\section{Statistical analysis}

Sex ratio was tested using a Chi-square $\left(\chi^{2}\right)$ test. Differences in the mean gonadosomatic index values between sexes were assessed for each month using a Mann-Whitney $U$ test. A Kruskal-Wallis nonparametric ANOVA was used to check for differences in pooled GI and PCI data among months. Relations among PCI, temperature, photoperiod and Chl $a$ (independent variables) with the reproductive cycle represented by GI (dependent variable) were assessed through a step-by-step multiple linear regression analysis (GLM) using STATA v1.2 statistical Software (Stata Corporation, College Station, TX, USA). Statistical significance was accepted at $p<0.05$ [4].

\section{Results}

Sea stars collected from both nearshore and offshore areas had different size compositions (Fig. 2). A. aranciacus major radius length $(R)$ ranged between 11 and $214 \mathrm{~mm}$ in nearshore samples, with a mean size of $81.40 \mathrm{~mm}(\mathrm{SD}=39.44)$, whereas $R$ ranged between 47 and $280 \mathrm{~mm}$ in offshore individuals, with a mean size of $161.33 \mathrm{~mm}$ ( $\mathrm{SD}=44.47)$. The length-weight relationship can be expressed as $W=0.0025 L^{2.22}\left(R^{2}=0.95\right.$; $\left.F_{(1.487)}=10,179, N=1365\right)$. Concerning shape variation, the length weight relationship revealed that weight is negatively allometric with length $(p<0.001, t=35.54)$, i.e., $A$. aranciacus becomes relatively more slender as it grows.

\section{Growth}

The $A$. aranciacus bimonthly length-frequency distributions at both bathymetrical ranges are shown in Fig. 3 . Recruitment nearshore was recorded twice in the whole period of study, in February 2010 and in April 2012. No recruitment or individuals smaller than $100 \mathrm{~mm}$ were found in the offshore samples. The progression of the identified cohorts over the 3 years of study can be seen in Fig. 4. In the nearshore samples (Fig. 4a) a cohort

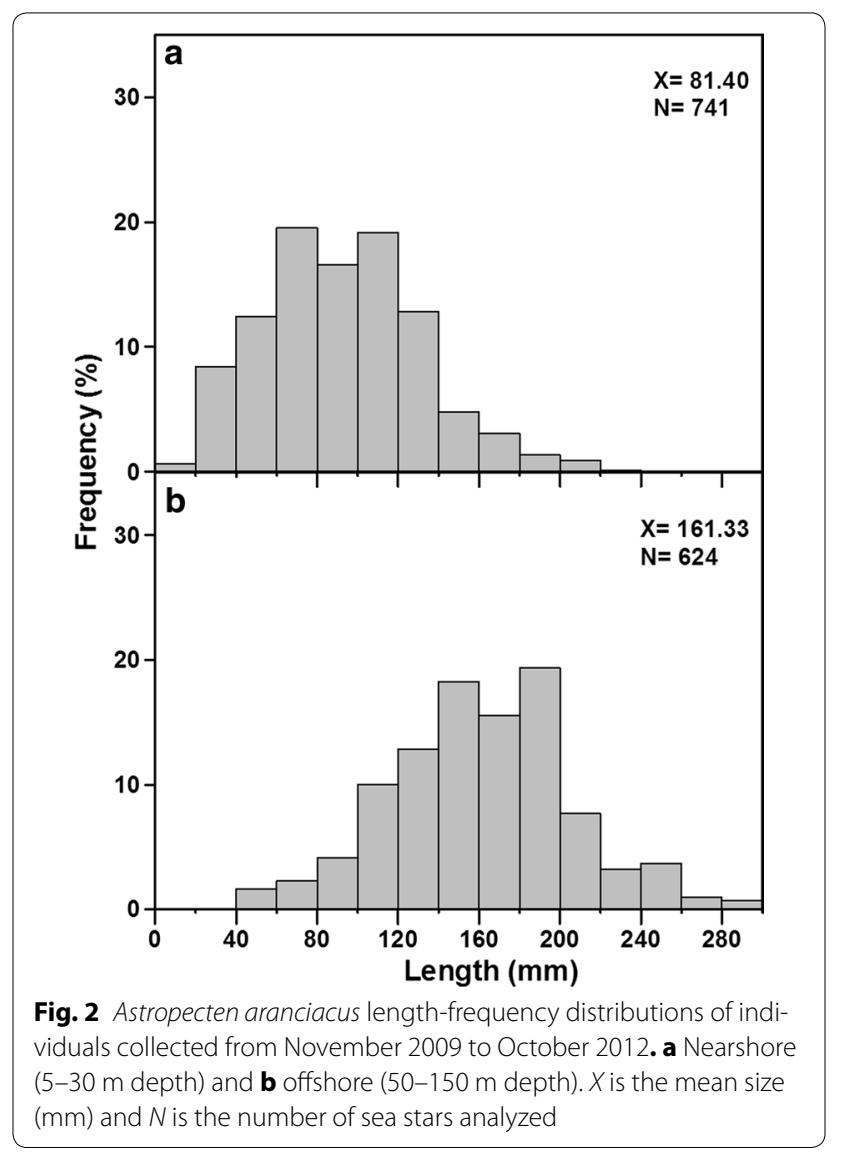




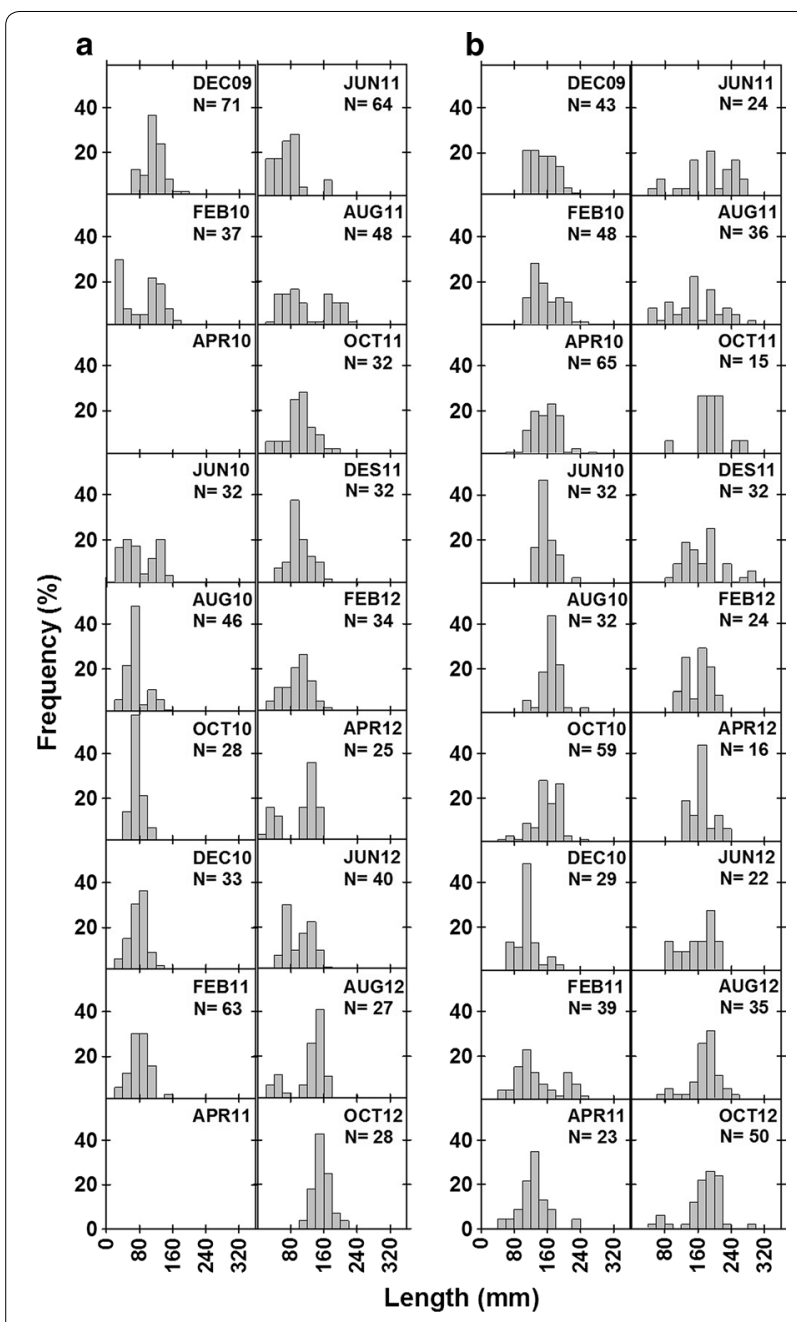

Fig. 3 Bimonthly size frequency distributions of A. aranciacus collected between November 2009 and October 2012 from Maresme coast. a Nearshore (5-30 m depth) and $\mathbf{b}$ offshore (50-150 m depth). Data for April 2010 and April 2011 nearshore are not presented because the sample size was $<10$ sea stars

(C-1) was observed from April $2012(R=47.56 \mathrm{~mm})$ to August $2012(R=69.15 \mathrm{~mm})$. Another cohort $(\mathrm{C}-2)$ was observed from February $2010(R=34.40 \mathrm{~mm})$ to October $2012(R=123.62 \mathrm{~mm})$, with a size increase of $89.22 \mathrm{~mm}$. A third cohort (C3) was detected from December 2009 $(R=113.02 \mathrm{~mm})$ to June $2010(R=115.51 \mathrm{~mm})$. In the offshore samples (Fig. 4b), we also observed three cohorts. The C-4 cohort was observed from December $2010(R=103.04 \mathrm{~mm})$ to October $2012(R=144.65 \mathrm{~mm})$; another cohort $(\mathrm{C}-5)$ was found from December 2009 $(R=125.58 \mathrm{~mm})$ to August $2012(R=171.08 \mathrm{~mm})$; and the last one (C-6) was occasionally detected from February $2011(R=206.5 \mathrm{~mm})$ to April $2012(R=217.64 \mathrm{~mm})$. Growth rates could be obtained following the mean
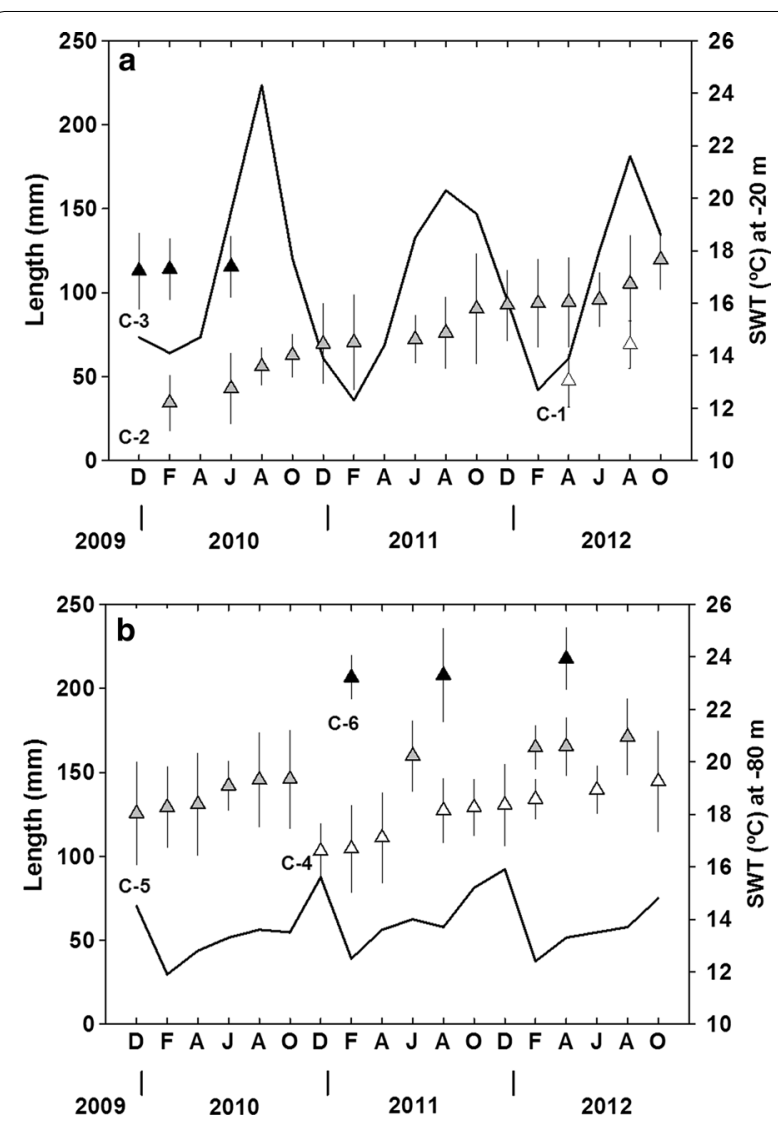

Fig. 4 Astropecten aranciacus growth between November 2009 and October 2012 estimated from bimonthly progression of mean length of each cohort $( \pm S D)$ in length-frequency distributions in both bathymetrical ranges: a 5-30 m and b 50-150 m. Each symbol corresponds to different sea star cohorts. In a white triangles cohort C-1, gray triangles $\mathrm{C}-2$ and black triangles $\mathrm{C}-3$; in $\mathbf{b}$ white triangles cohort C-4, gray triangles $C-5$ and black triangles $C-6$. The black line sea water temperature at $-20 \mathrm{~m}(\mathbf{a})$ and at $-80 \mathrm{~m}(\mathbf{b})$

length of the long lasting cohorts C-2, C-4 and C-5 over time. The nearshore $\mathrm{C}-2$ cohort showed higher growth rates during summer and autumn (18-24 $\mathrm{mm}$ from June to October) in the 3 years studied. The offshore cohort C-4 showed higher growth between February-August $2011(22.8 \mathrm{~mm})$ and February-October $2012(10.65 \mathrm{~mm})$. The offshore cohort C-5 showed higher growth between April and August 2010 (14.44 mm). The estimated von Bertalanffy growth parameters for nearshore individuals were $L_{\infty}=136.75 \mathrm{~mm}, k=0.44$ year $^{-1}$ and $t_{0}=0.0017$ $\left(N=741 ; R^{2}=0.73\right)$, whereas for offshore individuals they were $L_{\infty}=205 \mathrm{~mm}, k=0.32$ year $^{-1}$ and $t_{0}=0.0011$ $\left(N=624 ; R^{2}=0.82\right)$.

\section{Gonads morphology and development}

The reproductive system of $A$. aranciacus comprises two separate gonads in each arm (ten gonads in total). Each 
gonad was arranged as a series of tufts, located in and attached to the proximal part of each arm, near the disk on the inner face of the lateral wall, below the pyloric caeca, suspended in the celom along the entire length of the arm. Mature gonads were pale cream in males and deep yellow in females. The gonadal wall consisted of two-sac structures (the inner and the outer sacs) separated by the genital celom, which is typical for asteroids.

The five stages that characterize the gonadal development of $A$. aranciacus are the following:

Ovogenesis (Fig. 5). I-Recovery Stage Ovaries' lumen was partially filled with amorphous material, cell debris
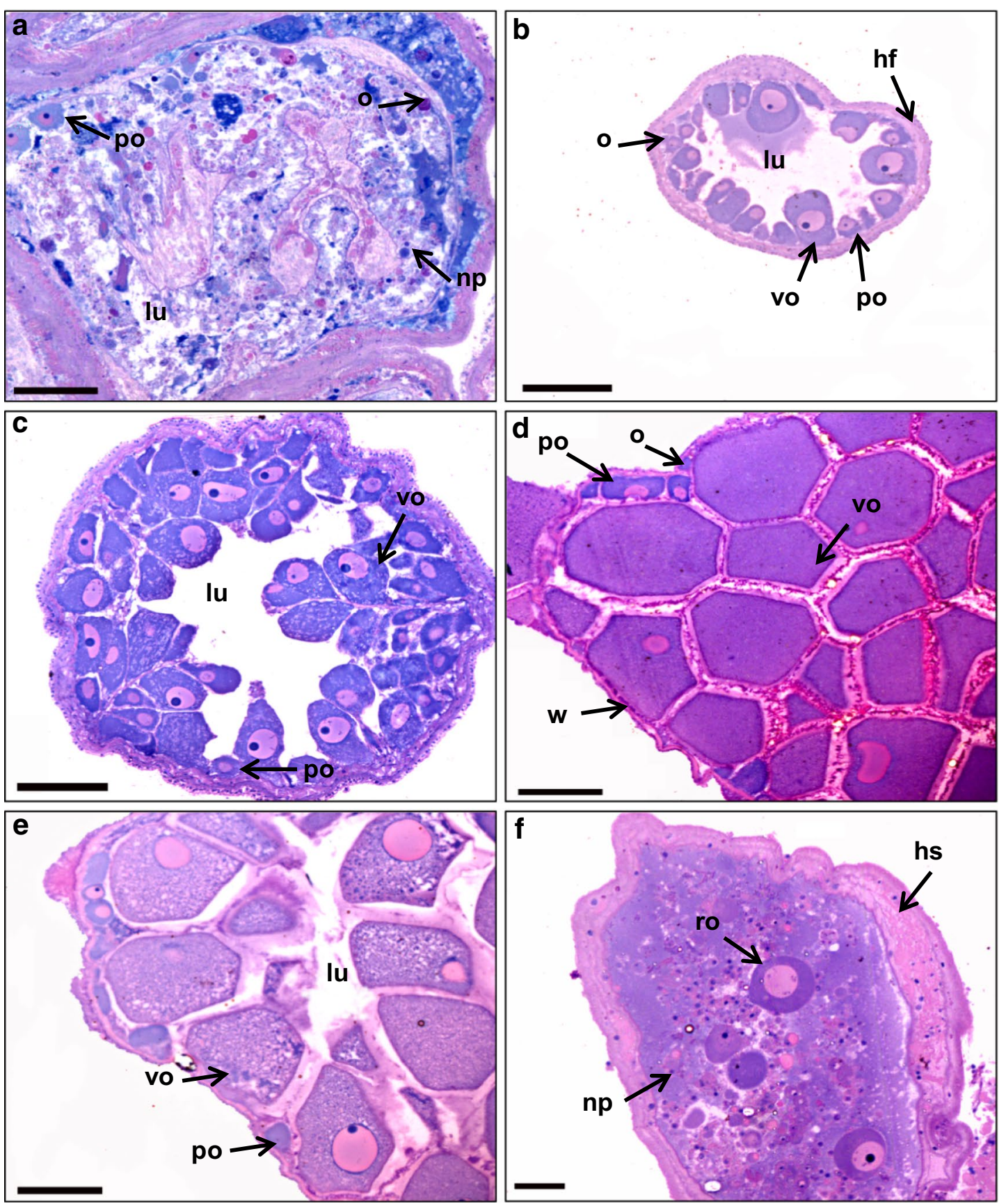

Fig. 5 Photomicrographs of A. aranciacus ovaries showing different gonadal stages: a Stage I, Recovery; b, c Stage II, Growing; d Stage III, Mature; e Stage IV, Partly Spawned; f Stage V, Spent. $h f$ hemal invaginations, hs hemal sinus, lu lumen, o oogonia, po previtellogenic oocyte, vo vitellogenic oocyte, ro relict oocyte, $n p$ nutritional phagocytes. Scale bars $500 \mu \mathrm{m}$ 
and phagocytes. The gonadal wall was thick, and the two-sac structures were evident; at advanced recovery stage the surface of the germinal epithelium was lined with oogonia and sometimes with early vitellogenic oogonia (Fig. 5a). II-Growing Stage Early in the growing stage (Fig. 5b), the ovarian surface epithelium was thick and mainly covered by previtellogenic oocytes, although some early vitellogenic oocytes could also be found. Late in the growing stage (Fig. $5 \mathrm{c}$ ), the ovarian surface epithelium appeared thinner, oocytes accumulated in the lumen and vitellogenic oocytes were dominant. Oocytes showed an eccentric nucleus (Fig. 5c). The cytoplasm of the oocytes appeared blue together with oogonia, whereas the nuclei were stained in pink. IIIMature Stage Ovaries were densely packed and stacked with fully grown oocytes in the lumen, and the surface epithelium appeared thin. Oogonia and previtellogenic oocytes were uncommon and restricted to the germinal layer. The gonadal wall was the thinnest observed in the whole reproductive cycle (Fig. 5d). IV-Partly Spawned Stage Ovaries were poorly packed with fully grown oocytes in the lumen with large empty spaces; previtellogenic oocytes were scarce and not exclusively restricted to the germinal layer. Relict oocyte debris and phagocytes were present in the lumen. The ovary wall remained thin (Fig. 5e). Sometimes atresia was observed. V-Spent Stage Ovaries were filled with amorphous material with relict oocytes, the gonadal wall became thicker, and the twosac structure was more evident. Relict oocyte debris and phagocytes were present in the lumen (Fig. 5f).

Spermatogenesis (Fig. 6). I-Recovery Stage Testes were small and remained contracted; the lumen was almost empty and partially filled with nutritive phagocytes; the gonadal wall was thick; and the two gonadal sacs were visible. Spermatogenic columns (consisting in spermatogonia) started to develop and grow (Fig. 6a). II-Growing Stage The testes had an intense spermatogenesis activity; they started to widen and became larger. Early in the growing stage, spermatogenic columns were projected into the central lumen and filled almost the totality of the volume; the gonadal wall began to shrink. As the growing stage progressed, testes enlarged and the number of spermatozoa increased from the border of the columns to the central lumen; at the same time the spermatogenic columns became larger as the gonadal wall shrank (Fig. 6b, c). III-Mature Stage Testes were densely packed and compressed with spermatozoa in the lumen, surrounded by very thin spermatogenic epithelium of spermatogenic columns. The wall of the testes was the thinnest observed in the whole reproductive cycle (Fig. 6d). IV-Partly Spawned Stage Testes looked similar to those in the mature stage but spermatozoa were poorly packed; there were spaces between patchy concentrations of spermatozoa in the lumen. Sometimes a gap between the peripheral spermatogenic layer and the central mass of spermatozoa was visible. The gonadal wall became thicker, and inner and outer sacs were visible again (Fig. 6e). V-Spent Stage Testes shrank and became smaller and contracted; the lumen was almost empty, with some nutritive phagocytes and isolated spermatozoa. The wall was thick and the two gonadal sacs became evident (Fig. 6h).

\section{Reproductive cycle}

Results showed that females in Stage I (Recovery) were present throughout the study. Ovaries in Stage II (Growing) were also found all year round except in spring (May 2011 and from March to May 2012) (Fig. 7a). The proportion of females with ovaries in Stage II began to increase in June for both study years, and the maximum frequency of occurrence (90\%) was recorded in September 2011. Accordingly, females with mature gonads (Stage III) were observed from October 2011 to May 2012, and most mature females $(>40 \%)$ were recorded between February and April. Partially spawned gonads (Stage IV) were observed from December to June, with the highest frequency being found in May 2012. The majority of the spent ovaries (Stage V) were found between March and July for both 2011 and 2012.

Similarly to females, males in Stage I (Recovery) were present throughout the study except for March 2012. Spermatogenesis (Stage II) started between August and September and lasted until January, but was dominant between October and December (Fig. 7b). In accordance, mature testes (Stage III) appeared afterward and were observed in some individuals from December to May. Partially spawned (Stage IV) individuals were found between January and July, with a higher frequency in April 2012. Though a few spent testes (Stage V) were observed in February 2012, most of the individuals in this reproductive stage were observed from March to August.

\section{Sex ratio and size at first maturity}

Sea stars did not show sexual dimorphism. A total of 312 individuals were collected from nearshore (87 females, 89 males and 136 immature) and 253 individuals from offshore (135 females, 116 males and 2 immature). The Chi-square $\left(\chi^{2}\right)$ test did not show significant differences between sexes; the ratio between males and females was almost 1:1 throughout the year in both bathymetrical ranges: nearshore $\left(\chi^{2}=10.186 d f=15 ; p>0.05\right)$ and offshore $\left(\chi^{2}=19.856 ; d f=16, p>0.05\right)$. The size of the smallest sea star with gonads was $R=56 \mathrm{~mm}$ for females and $R=55 \mathrm{~mm}$ for males. The size at first maturity ( $R 50 \%$ ) was estimated to be $R=112 \mathrm{~mm}$ considering both sexes together. 

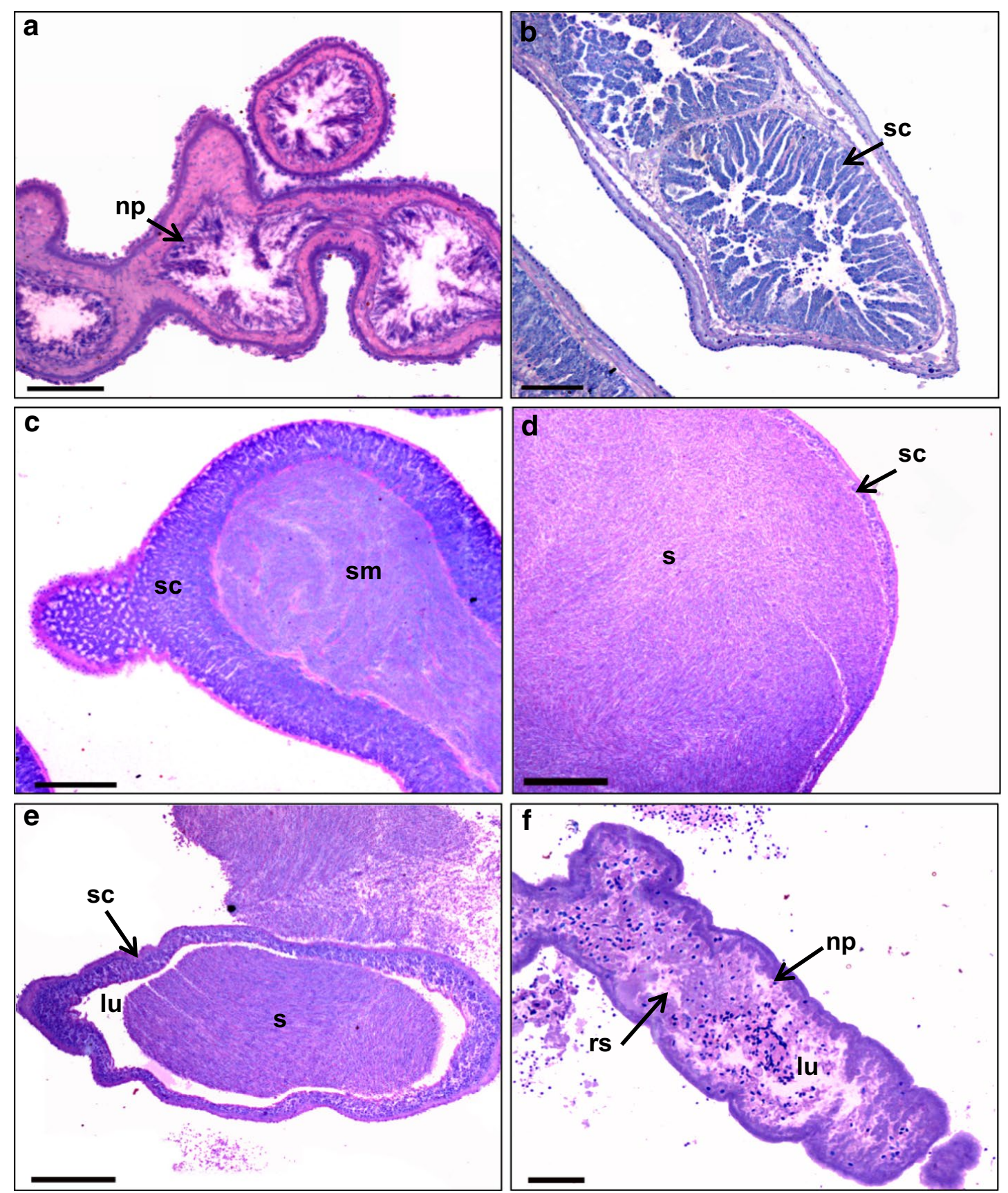

Fig. 6 Photomicrographs of A. aranciacus testes showing different gonadal stages: a Stage I, Recovery; b, c Stage II, Growing; d Stage III, Mature; e Stage IV, Partly Spawned; f Stage V, Spent. $h f$ hemal invaginations, hs hemal sinus, lu lumen, sc spermatogenic columns, sp spermatogonia, sm spermatids, s spermatozoa, rs residual spermatozoa, $n p$ nutritional phagocytes. Scale bars $50 \mu \mathrm{m}$

\section{Organ indices}

No significant differences between sexes were found when the monthly gonadal and pyloric caeca indices were compared (Mann-Whitney, $p>0.05$ ); values for both sexes were then pooled for further analyses. The gonadal index increased from $0.18 \pm 0.24$ in Stage
I (Recovery) to a maximal value of $5.6 \pm 4.42$ in Stage III (Mature) (Fig. 8). Once spawning occurred, the GI values declined progressively from Stage IV (Partly spawned) $(3.52 \pm 2.44)$ to Stage V (Spent) $(0.43 \pm 0.44)$. GI values for $A$. aranciacus showed significant differences between months $(H=110.07 ; d f=16, p<0.001)$ 


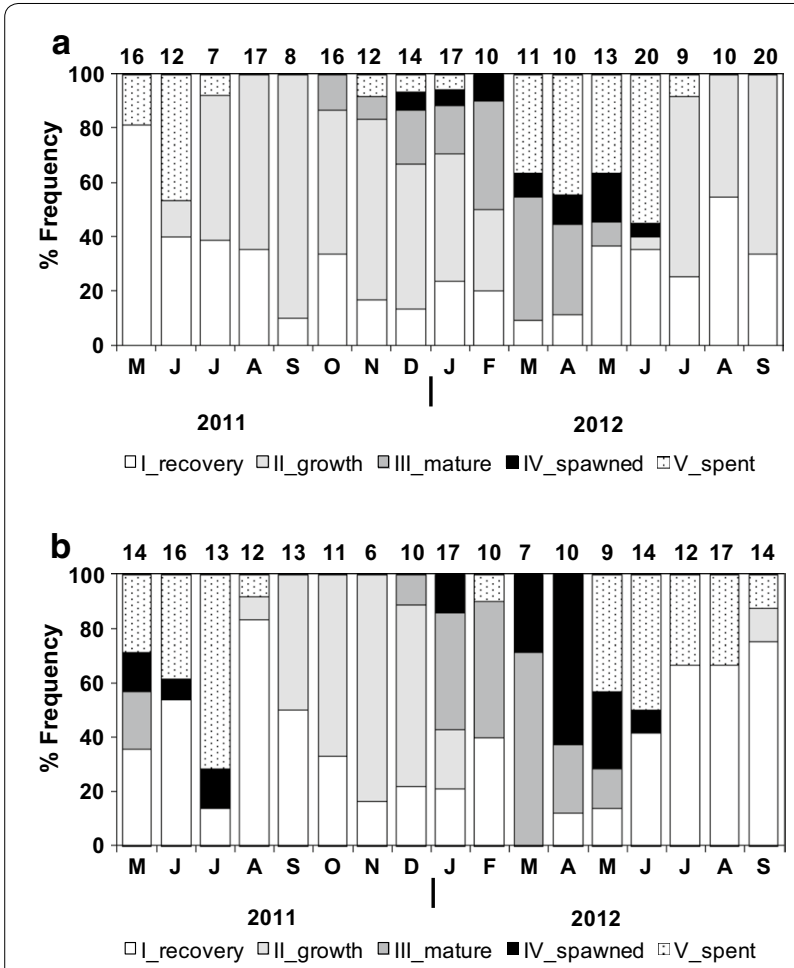

Fig. 7 Annual gametogenesis cycle of $A$. aranciacus between May 2011 and September 2012. a Females; b males. Numbers on the top of each column indicate the number of individuals analyzed monthly per sex

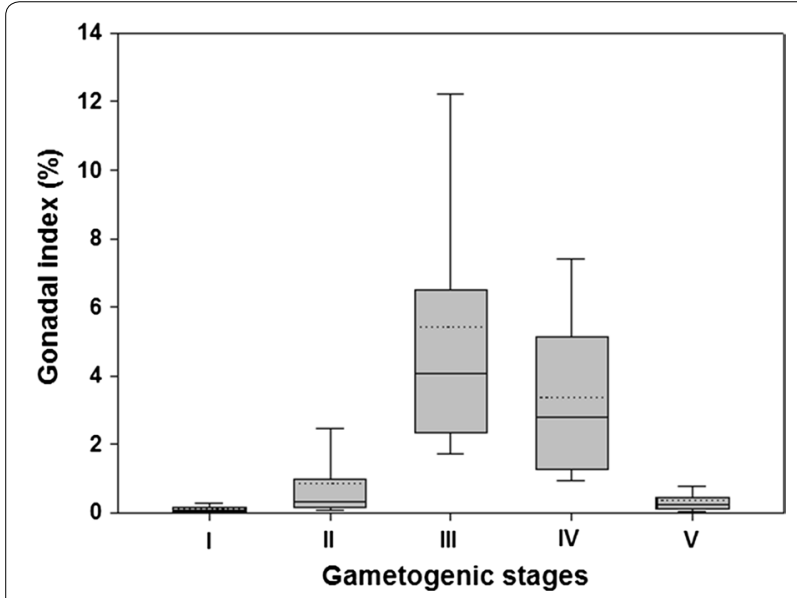

Fig. 8 Astropecten aranciacus variations in the gonadal index of different gametogenic stages. Stage I, Recovery; Stage II, Growing; Stage III, Mature; Stage IV, Partly Spawned; Stage V, Spent. The boundary of the box closest to zero the 25th percentile; the continuous line within the box marks the median; the discontinuous line within the box marks the mean; and the boundary of the box farthest from zero the 75th percentile. Whiskers (error bars) above and below the box the 95th and 5th percentiles
(Fig. 9). Monthly values revealed an increase from October 2011 to March 2012, when GI reached its maximum (3.62\%). After that peak it decreased until July $2012(0.14 \%)$. Significant differences were also observed among months for pyloric caeca index $(H=58.76 ; d f=16, p<0.001)$. The highest PCI values were recorded between March and May 2012 $(>4.5 \%)$, whereas the lowest were recorded in the summer months (June, July, August 2011, and July, August, September 2012). The surface sea water temperature (SSWT) at the study site had maximum values in summer months (July-September) and minimum values in winter months (January to March) (Fig. 10). Chl a monthly values recorded during our study period were lower between July and September, and two peaks were
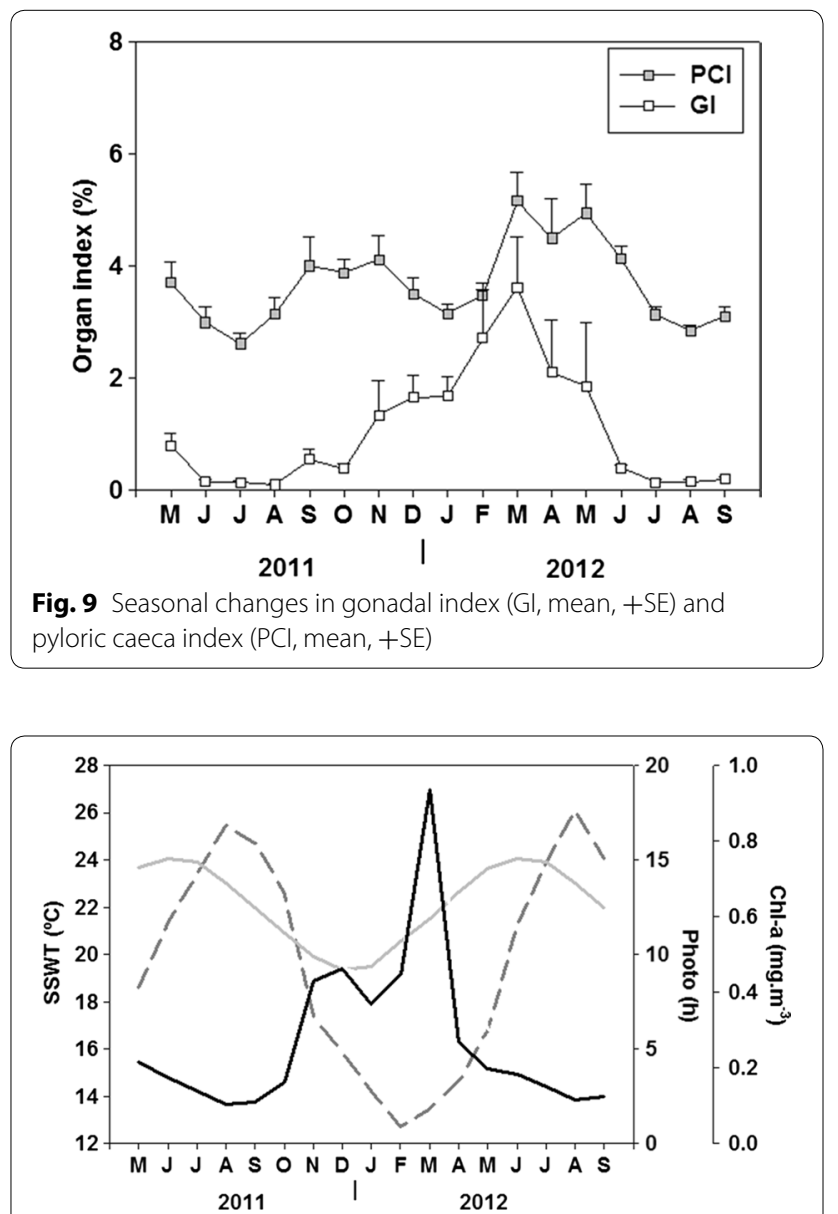

Fig. 10 Monthly mean of sea surface water temperature (SSWT; gray long dash); photoperiod (Photo; gray line), expressed in number of daylight hours every $24 \mathrm{~h}$; mean values of chlorophyll a (Chl a) concentration from May 2011 to September 2012 (black line) 
recorded: one in December $2011\left(0.46 \mathrm{mg} \mathrm{m}^{-3}\right)$ and one in March $2012\left(0.93 \mathrm{mg} \mathrm{m}^{-3}\right)$. The multiple regression analysis of GI with respect to the PCI and environmental variables was performed in two steps, resulting in the following model: $\mathrm{GI}=0.90+0.09 \mathrm{PCI}-0.03 \mathrm{SSWT}$. The model showed that the total explained variance over the GI in terms of the selected variables was $84.58 \%\left(R^{2}=0.8458, R=0.88, p<0.05\right)$, indicating that the PCI and surface sea water temperature (SSWT) are correlated with GI. The photoperiod and Chl $a$ did not show any correlation with GI; however, the spawning season coincided with the time period of highest levels of Chl $a$.

\section{Discussion}

Astropecten aranciacus individuals smaller than $80 \mathrm{~mm}$ were abundant in shallow waters (5-30 $\mathrm{m}$ depth), whereas large individuals $(>130 \mathrm{~mm})$ were observed mostly offshore (50-150 m depth). The use of different gears to sample both bathymetric ranges in this study may have caused bias collecting small sizes offshore, but no bias for larger sizes in shallow waters could occur. Therefore, any bigger individuals of $A$. aranciacus inhabiting depths between 5 and $30 \mathrm{~m}$ would have been collected in our sampling. Burla et al. [8] studied the activity pattern of $A$. aranciacus by scuba diving in Sardinia (Italy) and found only small specimens. These authors suggested that adults and juveniles may dwell in different parts of the ecological zone occupied by the species, the fully grown specimens invading the deeper waters. Our study is the first to sample most of the bathymetrical distribution range of $A$. aranciacus, allowing us to confirm a bathymetrical segregation related to size in this species. Ventura and Fernandes [45] reported size-depth trends for Astropecten brasilensis in Cabo Frio, Brazil, where they found larger individuals with depth. Segregation by size were also reported for the asteroid Protoreaster nodosus, whose large specimens were found between 0 and $33 \mathrm{~m}$ depth, whereas small specimens were exclusively found in shallower habitats $(<5 \mathrm{~m})$ [6]. Young sea stars might prefer shallow areas where food and shelters to avoid predation are usually more abundant [30].
The major radius length-weight relationship showed a negative allometry in $A$. aranciacus, thereby they invest more energy in body enlargement than in fattening, as previously observed in other Astropecten species $[19,46]$ and sea stars genera [6, 7]. Absolute growth has been extensively analyzed in sea stars (see references in Lawrence and Lane [29], but few studies have established growth rates in natural populations of the genus Astropecten [15, 35, 40, 43] (Table 1). The studied $A$. aranciacus population exhibited a seasonal growth pattern, slightly different for nearshore and offshore cohorts. Individuals living offshore had a longer growth period but their growth rate was slower, as is expected in older specimens. Seasonal variation in growth had been described for other Astropecten species, which usually showed a decrease in growth rate associated with gonad maturation [15, 35, 43]. According to our study, the growth rate for $A$. aranciacus seems to be related to sea water temperature as higher growth rates were recorded nearshore when sea water temperature was also higher. Moreover, sea water temperature increased slightly from February to December offshore, coinciding with the period of highest growth rate for those cohorts. Ventura [44] reported that the decrease in growth rate of A. brasiliensis and A. cingulatus coincided with the seasonal upwelling period in Brazil, suggesting that it could be related to sea water temperature decline. Other factors such as the amount and quality of available food can also affect growth, as reported by Guillou and Guillaumin [20] in Asterias rubens.

The $A$. aranciacus population studied herein seems to have variable reproductive and recruitment success. Sea stars as other echinoderms show usually a high degree of spatial and temporal variability in settlement and recruitment [24]. Nil or low recruitment over a period of time is not surprising in $A$. aranciacus, i.e., Hörstadius [22] reported that they have a long pelagic larval phase (80 days) under laboratory conditions. During this period Astropecten larvae were subject to hydrological processes which may displace them long distances [15, 41]. Regarding the main hydrological process in the study area, the prevailing currents are controlled by the cyclonic

Table 1 Estimated parameters of the von Bertalanffy growth equation for Astropecten species at different study areas

\begin{tabular}{lllllll}
\hline Species & Depth $(\mathbf{m})$ & $\boldsymbol{L}_{\boldsymbol{\infty}}(\mathbf{m m})$ & $\boldsymbol{K}$ (year $\left.^{-\mathbf{1}}\right)$ & $\boldsymbol{t}_{\mathbf{0}}$ & Study area & References \\
\hline A. latespinus & $0.1-5$ & 42.02 & 0.04 & 0.0325 & Fukuoka, Japan (Sea of Japan) & Nojima [35] \\
A. cingulatus & $45-60$ & 81 & 1.2 & - & Maçambaba Beach, Brasil (SW Atlantic) & Ventura [43] \\
A. brasilensis & $45-60$ & 140 & 0.75 & - & Maçambaba Beach, Brasil (SW Atlantic) & Ventura [43] \\
A. marginatus & $6-15$ & 65 & 0.50 & - & Guarana, Brasil (SW Atlantic) & Tavares et al. [40] \\
A. aranciacus & $5-30$ & 136.75 & 0.44 & 0.0017 & Maresme Coast, Spain (NW Mediterranean) & Present study \\
A. aranciacus & $50-150$ & 205 & 0.32 & 0.0011 & Maresme Coast, Spain (NW Mediterranean) & Present study \\
\hline
\end{tabular}


eddy of the western Mediterranean derived from the Liguro-Provencal current [34]. Although local larvae could be transported away to the southwest, recruitment was already observed 2 of the 3 years studied on the nearshore area, indicating that some larvae settled. The lack of recruitment offshore may be related to the absence of favorable environmental conditions for larvae settlement and/or to predation on juveniles. During different samplings, offshore, we observed the presence of Luidia ciliaris and Tethyaster subermis, potential predators [23] that could play an important role in the recruitment failure of $A$. aranciacus.

Results showed that both $A$. aranciacus sexes had a synchronous gametogenesis but females reached the maturity stage slightly earlier than males, in accordance with previous results obtained in Asterias amurensis by Byrne et al. [9]. The studied $A$. aranciacus population did not differ significantly in the male-female proportions, coinciding with previous results in other sexually reproducing asteroids (since sex-ratios can be highly biased in the case of asexual asteroids) $[4,26]$. The development of the $A$. aranciacus gonads reflected that mature and partially spawned individuals remained for an extended period of time. The GI value was highest in March, indicating that during that month the gonads of $A$. aranciacus were in maximum development. Spawning likely started in March in part of the population and extended until June-July, in accordance with the decrease in GI and the presence of post-spawning individuals evidenced by the histological analysis of the gonads.

In general the reproductive cycles of sea stars are correlated with a combination of endogenous (i.e., hormones) and exogenous factors (i.e., temperature, photoperiod, food availability, lunar cycle, tidal flux and light intensity) [33]. Sea star oocytes at the peak of the breeding season are fully grown and arrested at prophase I of meiosis [39]. Hormonal stimulation (methyladenine, 1-MA) from the adhering follicle cells reenter the oocytes in the meiotic cycle before being spawned into seawater [25]. However, the direct influence of exogenous factors remains still poorly understood [33]. In Astropecten species, breeding season commonly coincides with the increase in water temperatures in temperate areas [15]. For instance, these authors reported that the spawning periods for $A$. irregularis coincided with the rise from 8 to $15^{\circ} \mathrm{C}$ in seawater temperatures (North Wales). Our results showed a similar pattern, because the spawning season of $A$. aranciacus likely began in spring, when the sea water temperatures started to increase in the Mediterranean. We also observed that the beginning of $A$. aranciacus spawning coincided with the highest $\mathrm{Chl} a$ concentration in the sea water, which was caused by the spring phytoplankton bloom typical of the Mediterranean Sea. The coincidence between the highest phytoplankton concentration and the spawning has been previously described in other echinoderms, but it is rare in sea stars [33]. The majority of the species of the genus Astropecten have planktonic larvae (bipinnaria). Bipinnaria larva nourish essentially on detritus, bacteria, phytoplankton (mainly small diatoms and small flagellates) and small zooplankton [1]. The synchronism between the spawning season of $A$. aranciacus, and the phytoplankton bloom could be a strategy to guarantee higher survival of early developmental stages.

An inverse correlation between GI and PCI has usually been described in most sea stars, suggesting the transfer of nutrients from the pyloric caeca to the gonads during gametogenesis [29]. However, this interaction has not been observed in species inhabiting areas with stable environmental conditions [4]. This relationship was not observed in the studied $A$. aranciacus population despite the fact that it inhabits a seasonally changing environment, in accordance with the results obtained by Ventura et al. [48] in $A$. cingulatus. Individuals of $A$. aranciacus collected in the offshore zone of the study area had large amount of preys in the stomach throughout the year. Most of these prey items were the venerid Timoclea ovata ( $>55 \%$, abundance in 224 sea stars analyzed), and each sea star stomach contains a mean of 49 T. ovata items of a mean size of $5.77 \mathrm{~mm}(\mathrm{SD}=5.52, N=9682)$ [2]. Therefore, food does not seem to be a limiting factor in the Maresme coast, suggesting that sea stars do not need to store large amounts of nutrients in the pyloric cecum, because nutrients can be easily obtained from the environment throughout all year. This suggests for $A$. aranciacus an "income breeding" reproductive strategy rather than "capital breeding", i.e., reproduction is financed using current energetic income and not from stored energetic capital. This strategy may explain why an inverse correlation between GI and PCI was not observed in this population.

Our findings provide a better understanding of the biology of $A$. aranciacus in the NW Mediterranean Sea and are also relevant for the future conservation of this sea star, since its populations seem to decrease in some places of the Mediterranean Sea.

\section{Authors' contributions \\ All co-authors carried out the adquisition, analysis and interpretation of data, drafting and criticalrevision of the Manuscript.}

\footnotetext{
Author details

${ }^{1}$ Institut de Ciències del Mar (CSIC), Passeig Marítim de la Barceloneta, 37-49, 08003 Barcelona, Spain. ${ }^{2}$ Universitat Autònoma de Barcelona (UAB), Campus de Bellaterra, Edifici B, 08193 Cerdanyola del Vallès, Barcelona, Spain. ${ }^{3}$ Instituto Español de Oceanografía, Centre Oceanogràfic de Balears, Moll de Ponent $s / n$, 07015 Palma de Mallorca, Spain.
} 


\section{Acknowledgements}

This study is part of the doctoral dissertation of MB. We are grateful to the fishermen 'Confraria de Pescadors d'Arenys', in particular the clam dredge fishermen (Miguel Angel Ruiz Navas, Jose Luís López Ramírez, Mauricio Pulido and their sailors), and Jaume Germà from the bottom trawl fleet. We are also grateful to all sampling participants: Lucía Martínez, Marta Coca, Eduard Albella and Nil García. We deeply thank Anabel Colmenero for her advice and tips on histology techniques and for her constructive comments and suggestions on reproductive biology. We are very grateful to Dr. Francesc Peters for providing us with the chlorophyll data. The authors also thank Puertos del Estado (Instituto Geográfico Nacional, Ministerio de Fomento) for the environmental data and Raquel Ubach (Autonomous University of Barcelona) for the help with the map.

\section{Competing interests}

The authors declare that they do not have competing interests.

Received: 22 April 2015 Accepted: 28 October 2015

Published online: 20 April 2016

\section{References}

1. Ayukai T. Resource availability to the larvae of the crown-of-thorns starfish in Great Barrier Reef waters: an overview. In: Engelhardt U, Lassig $B$, editor. The possible causes and consequences of outbreaks of crownof-thorns starfish. Great Barrier Reef Marine Authority Workshop Series; 1993. p. 21-35.

2. Baeta M. Ecology of some keystone invertebrates inhabiting shallow soft bottom communities of the Maresme coast (NW Mediterranean Sea). Dissertation, University of Barcelona; 2015.

3. Baeta M, Ramón M. Feeding ecology of three species of Astropecten (Asteroidea) coexisting on shallow sandy bottoms of the northwestern Mediterranean Sea. Mar Biol. 2013;160:2781-95.

4. Benítez-Villalobos F, Martínez-García M. Reproductive biology of the starfish Pharia pyramidatus (Echinodermata: Asteroidea) from the Mexican tropical Pacific. J Mar Biol Assoc UK. 2012;92:1409-18.

5. Bhattacharya PK. Efficient estimation of a shift parameter from grouped data. Ann Math Stat. 1967;38:1770-87.

6. Bos AR, Gumanao GS, Alipoyo JCE, Cardona LT. Population dynamics, reproduction and growth of the Indo-Pacific horned sea star, Protoreaster nodosus (Echinodermata; Asteroidea). Mar Biol. 2008;156:55-63. doi:10.1007/s00227-008-1064-2.

7. Bos AR, Gumanao GS, Van Katwijk MM, Mueller B, Saceda MM, Tejada RP. Ontogenetic habitat shift, population growth, and burrowing behavior of the Indo-Pacific beach star, Archaster typicus (Echinodermata; Asteroidea). Mar Biol. 2011;158:639-48.

8. Burla H, Ferlin V, Pabst B, Ribi G. Notes on the ecology of Astropecten aranciacus. Mar Biol. 1972;14:235-41. doi:10.1007/BF00348285.

9. Byrne M, Morrice MG, Wolf B. Introduction of the northern Pacific asteroid Asterias amurensis to Tasmania: reproduction and current distribution. Mar Biol. 1997;127:673-85. doi:10.1007/s002270050058.

10. Carvalho A, Ventura C. The reproductive cycle of Asterina stellifera (Möbius) (Echinodermata: Asteroidea) in the Cabo Frio region, southeastern Brazil. Mar Biol. 2002;141:947-54. doi:10.1007/ s00227-002-0881-y.

11. Christensen AM. Feeding biology of the sea star Astropecten irregularis Pennat. Ophelia. 1970;8:1-134.

12. Conand C. Sexual cycle of three commercially important holothurian species (Echinodermata) from the lagoon of New Caledonia. Bull Mar Sci. 1981;31:523-43.

13. Díaz Jl, Maldonado A. Transgressive sand bodies on the Maresme continental-shelf, western Mediterranean-sea. Mar Geol. 1990;91:53-72.

14. Ercilla G, Estrada F, Casas D, Durán R, Nuez M, Alonso B, Farrán M. The El Masnou infralittoral sedimentary environment (Barcelona province, NW Mediterranean Sea): morphology and Holocene seismic stratigraphy. Sci Mar. 2010;74:179-96.

15. Freeman SM, Richardson CA, Seed R. Seasonal abundance, spatial distribution, spawning and growth of Astropecten irregularis (Echinodermata: Asteroidea). Estuar Coast Mar Sci. 2001;53:39-49.
16. Gayanilo FCJ, Sparre P, Pauly D. FAO-ICLARM Stock Assessment Tools II (FiSAT II). Revison version. User's guide. Rome: FAO; 2005.

17. Giese AC. On the biochemical constitution of some echinoderm. In: Boolootian RA, editor. Physiology of echinodermata. New York: Interscience; 1966. p. 757-96.

18. Grant A, Tyler PA. An analysis of the reproductive pattern in the sea star Astropecten irregularis Pennant from the Bristol Channel. Int J Invertebr Reprod Dev. 1986;93:345-61.

19. Guilherme P, Rosa L. Seasonal variation in body size and diet of the sea star Astropecten marginatus (Paxillosida, Astropectinidae) off coast of Paraná, Southern Brazil. Rev Biol Trop. 2013;62:59-68.

20. Guillou M, Guillaumin A. Variations in the growth rate of Asterias rubens (L.) from west and south Brittany (France). In: Keegan BF, O'Connor BDS, editor. Proceeding of the 5 th international echinoderms conference. Rotterdam: A.A. Balkema; 1984. p. 513-21.

21. Gulland JA. Fish stock assessment: a manual of basic methods. Chichester: Wiley; 1983.

22. Hörstadius S. Über die Entwicklung von Astropecten aranciacus L. Mar Ecol PSZNI. 1938;17:221-312.

23. Jangoux M, Lawrence JM. Echinoderm nutrition. Rotterdam: A.A. Balkema; 1982.

24. Jangoux M, Lawrence J. Echinoderm studies 6. Rotterdam: A.A. Balkema; 2001

25. Kanatani H. Maturation-inducing substance in starfishes. Int Rev Cytol. 1973;35:253-98.

26. Kim YS. Histological observations of the annual change in the gonad of the starfish, Asterias amurensis. Fac Fish Hokkaido Univ. 1968;19:97-108.

27. Komatsu M, Nojima S. Development of the seastar, Astropeten gisselbrechti Doderlein. Pac Sci. 1985;39:274-82.

28. Lawrence JM. Starfish: biology and ecology of the Asteroidea. Baltimore: The Johns Hopkins University Press; 2013.

29. Lawrence J, Lane J. The utilization of nutrients by postmetamorphic echinoderms. In: Jangoux M, Lawrence J, editors. Echinoderm nutrition. Rotterdam: Balkema Press; 1982. p. 331-71.

30. Manzur T, Barahona M, Navarrete SA. Ontogenetic changes in habitat use and diet of the seastar Heliaster helianthus on the Coast of central Chile. J Mar Biol Assoc U K. 2010;90:537-46.

31. Marion KR, Watts SA, McClintock JB, Schimer G, Hopkins TS. Seasonal gonad maturation in Astropecten articulatus from the Northern Gulf of Mexico. In: Mooi R, Telford M, editors. Echinoderms. San Francisco: A.A. Balkema; 1998. p. 279-84.

32. McClary DJ, Mladenov PV. Reproductive pattern in the brooding and broadcasting sea star Pteraster militaris. Mar Biol. 1989;103:531-40. doi:10.1007/bf00399585.

33. Mercier A, Hamel J. Endogenous and exogenous control of gametogenesis and spawning in echinoderms. Adv Mar Biol. 2009;55:1-291.

34. Millot C. Circulation in the western Mediterranean Sea. J Mar Syst. 1999;20:423-42.

35. Nojima S. Ecological studies of the sea star Astropecten latespinosus Meissner II. Growth rate and differences in growth pattern of immature and mature sea stars. Publ Amakusa Mar Biol Lab Kyushu Univ. 1982;62:85-94.

36. Ribi G, Burla H, Ochsner P. Beobachtungen über vorkommen, abundanzen und körpergrößen von mediterranen arten der gattung Astropecten. Helgol Wiss Meeres. 1976:28:304-17.

37. Ribi G, Scharer R, Ochsner P. Stomach contents and size-frequency distributions of two coexisting sea star species, Astropecten aranciacus and $A$. bispinosus, with reference to competition. Mar Biol. 1977;43:181-5.

38. Rubilar T, Pastor de Ward CT, Díaz de Vivar ME. Sexual and asexual reproduction of Allostichaster capensis (Echinodermata: Asteroidea) in Golfo Nuevo. Mar Biol. 2005;146:1083-90. doi:10.1007/s00227-004-1530-4.

39. Santella L, Limatola $L$, Thai Chun J. Chapter: 13 . Actin cytoskeleton and fertilization in starfish eggs. In: Sawada H, Inoue N, Iwano M, editors. Sexual reproduction in animals and plants. Berlin: Springer; 2014. p. 141-55.

40. Tavares Y, Silvéiro G, Borges P, Braz B, Borzone C. Dinâmica populacional de Astropecten marginatus (echinodermata:asteroidea) no sul do Brasil XII Congreso Latino-Americano de Ciencias do Mar Florianópolis; 2007.

41. Thorson G. Reproduction and larval development of Danish marine bottom invertebrates. Medd Kom Dan Fisk Havunders Plankton. 1946:4:1-523.

42. Tortonese E. Echinodermata. Italia: Calderini Bologna; 1965.

43. Ventura C. Gametogenesis and growth of two a Astropecten species from a midshelf upwelling region, Cabo Frio, Brazil. In: Candia Carnevali MD, 
Bonasuro F, editors. Research proceedings of the 5 th European conference on echinoderms. Milan: A.A. Balkema; 1999. p. 167.

44. Ventura C. Astropecten. In: Lawrence JM, editor. Starfish: biology and ecology of the Asteroidea. Baltimore: The Johns Hopkins University Press; 2013. p. 101-8.

45. Ventura C, Fernandes F. Bathymetric distribution and population size structure of paxillosid seastars (Echinodermata) in the Cabo Frio upwelling ecosystem of Brazil. Bull Mar Sci. 1995;56:268-82.

46. Ventura C, Junqueira A, Fernandes F. The relation between body size and number of prey in starfish (Echinodermata: Asteroidea). In: David B, Gille A, Féral J, Roux M, editors. Echinoderms through time. Rotterdam: A.A. Balkema; 1994. p. 375-80

47. Ventura C, Falcao A, Santos J, Fiori C. Reproductive cycle and feeding periodicity in the starfish Astropecten brasiliensis in the Cabo Frio upwelling ecosystem (Brazil). Int J Invertebr Reprod Dev. 1997;31:135-41.
48. Ventura C, Santos J, Falcao A, Fiori C. Reproduction and food intake in Astropecten cingulatus in the upwelling environment of Cabo Frio. In: Mooi R, Telford M, editor. Echinoderms: San Francisco proceedings of the ninth international echinoderm conference. San Francisco, California, USA: A.A. Balkema; 1998. p. 313-18.

49. Zulliger DE, Lessios HA. Phylogenetic relationships in the genus Astropecten Gray (Paxillosida: Astropectinidae) on a global scale: molecular evidence for morphological convergence, species-complexes and possible cryptic speciation. Zootaxa. 2010;2504:1-19.

50. Zulliger D, Tanner S, Ruch M, Ribi G. Genetic structure of the high dispersal Atlanto-Mediterranean sea star Astropecten aranciacus revealed by mitochondrial DNA sequences and microsatellite loci. Mar Biol. 2009;156:597-610. doi:10.1007/s00227-008-1111-z.

\section{Submit your next manuscript to BioMed Central and we will help you at every step:}

- We accept pre-submission inquiries

- Our selector tool helps you to find the most relevant journal

- We provide round the clock customer support

- Convenient online submission

- Thorough peer review

- Inclusion in PubMed and all major indexing services

- Maximum visibility for your research

Submit your manuscript at www.biomedcentral.com/submit

(O) Biomed Central 